\title{
Organizational Diversity Commitment: A Web-Based Investigation
}

\author{
Anselmo Ferreira VASCONCELOS \\ Independent researcher, São Paulo, Brazil \\ afv@uol.com.br
}

\begin{abstract}
The purpose of this study is to examine organizational held values and beliefs related to diversity, particularly derived from the corporate websites of the best companies to work for in Brazil, that is, an annual edition published by Época magazine along with the Great Place to Work ${ }^{\circledR}$ Institute (GPTW). Therefore, this study focuses on how these companies are addressing the themes of diversity, inclusion, and discrimination through their organizational discourses. More specifically, it draws exclusively on the statements and corporative documents posted on their websites. Overall, findings indicated that barely 57 (43.8\%) of the 130 companies awarded by GPTW-Época 2014's list showed some interest in providing a discourse toward diversity/inclusion issues in their websites. Moreover, no more than 31 firms (54.4\% of the sample) depicted a compelling or somewhat acceptable diversity discourse (i.e., an indication that this issue has been addressed, yet it requires additional measures). Taken as a whole, results suggest that diversity appears to be a topic of low status in the most of the best organizations to work for in Brazil. In general, multinational corporations tend to put aside desirable aspects on their statements, even so they enact better diversity, inclusion, and anti-discrimination discourses than Brazilian firms.
\end{abstract}

Keywords: Brazil, diversity, inclusion, discrimination, leadership, values.

Please cite the article as follows: Vasconcelos, A.F. (2017), "Organizational Diversity Commitment: A WebBased Investigation", Management \& Marketing. Challenges for the Knowledge Society, Vol. 12, No. 3, pp. 474-499, DOI: 10.1515/mmcks-2017-0029.

\section{Introduction}

Although the capability of "managing and understanding diversity and difference" has been advocated as "one of the foremost competencies of tomorrow's organizations" (Weaver, 2008, p. 111), growing evidence has indicated that such a concern has not been taking place. Definitively, diversity orientation is a path to integrate diverse perspectives and experiences into the whole of organizational life. By drawing on diversity orientation (i.e., work design, staffing, training, and compensation), an organization signals that diversity is unconditionally valued as a core part of its structure (Richard and Johnson, 2001). Similarly, the development of higher aggregate level of diversity climate within organizations relies on the adoption of diversity programs (Herdman and McMillan-Capehart, 2010). Notwithstanding all efforts that have been done throughout the years, there is some evidence indicating that "organizations continue to do a poor job of managing diversity" (Roberson and Kulik, 2007, p. 24, emphasis added). Accordingly, by demonstrating how diversity is tied directly to the organization's business strategy one provides a link between the diversity initiative and organizational outcomes (Jayne and Dipboye, 2004, p. 417). Either way, it is clear that leadership commitment is crucial to any successful diversity initiative (Dreachslin, 2007; Ng and Wyrick, 2011; Weaver, 2008).

Despite the fact that the field of organizational diversity focuses mainly on the work group level, i.e., by examining how group composition affects group performance, cohesion, social interaction, group members' commitment, satisfaction, and other indicators of subjective well-being (van Knippenberg and Schippers, 2007), it is also undeniable that many other dimensions of diversity deserve research attention. For instance, Roberge et al. (2011) suggest that the process of "Valuing diversity begins by 
incorporating a diversity statement into the organizational mission statement, and promoting consistent organizational values [...]" (p. 4, emphasis added). Such a claim evokes the importance of discourse as an organizational resource. In this regard, diversity management (DM) should need to take advantage of (1) the organizational discourses in order to deliver its promises (2) as well as to avoid taking the risk of being labeled just as another useless management fad (Heres and Benschop, 2010).

In a related vein, Roberge et al. (2011) posit that the usage of symbolic management is a form of valuing diversity. Thus, organizations may show the level of their commitment to diversity by incorporating it into their organizational mission statements (i.e., by expressing its value, explaining why it is important, emphasizing "us" as the group) and/or other organizational reports. Scholars have proposed that a DM approach may be addressed by means of three alternatives (Olsen and Martins, 2012). Firstly, it may focus on leveraging diversity in order to achieve business-related outcomes; therefore, this alternative embraces diversity only as an instrumental value. Secondly, rather than approaching diverse workforce as a business goal, organizations may prefer to consider it as a terminal value. Finally, organizations may encompass diversity as both terminal and instrumental values, that is, a dual value. Such an approach holds that DM is "good for business" as well as "important in its own right" (Olsen and Martins, 2012, p. 1171). In parallel, researchers have investigated corporate websites in order to find if the content of their organizational mission statements and other reports someway incorporate diversity concerns (e.g., Guerrier and Wilson, 2011; Heres and Benschop, 2010; Meriläinen et al., 2009; Point and Singh, 2003; Singh and Point, 2004; Wallace et al., 2014) or discourses of diversity (Zanoni and Janssens, 2015). Overall, it is assumed that the documents aforementioned depict a coherent organizational discourse toward diversity and related issues, given the growing relevance of this topic.

Corporate websites also constitute a suitable tool to communicate organizational held values and beliefs related to diversity for stakeholders. Further, it is proposed that "the use of websites for eliciting formal corporate communication does present an interesting entrance into how the company wishes to present and identify itself [...]" (Heres and Benschop, 2010, p. 453). Having said that, the purpose of this study is to examine these aspects, particularly derived from the corporate websites of the best companies to work for in Brazil, that is, an annual edition published by Época magazine along with the Great Place to Work ${ }^{\circledR}$ (GPTW) Institute. It is worth pointing out that Brazil is one of the BRICS and, as such, it is one of the major emerging economies of the planet. Taking into account that these companies are regarded as the best employers of the country, this investigation tries to answer the following research question: What kind of DM discourses have they been depicting in their websites?

This study contributes to the theory by outlining how the discourse of diversity, inclusion, and discrimination topics are handled by that very special cohort of organizations operating in Brazil, as well as identifying the most relevant themes. Some studies have focused on Brazilian context (e.g., Fleury, 1999, 2000; Jabbour et al., 2011; Vasconcelos, 2012; 2016a, b, forthcoming) and overall the findings have suggested a slow progress toward diversity. Nevertheless, this is the first inquiry that focuses specifically on the 130 best companies to work for (i.e., organizations that are highly acknowledged by their human resource policies) and their DM discourses, as well as presenting a conceptual typology based on the results. In order to accomplish such goal, the following section presents a brief literature review. Second, it addresses the method in which this study is grounded. Third, in light of the GPTW-Época 2014's list, it presents 
the results of an analysis focusing exclusively on corporate websites' content. Fourth, the discussion section explores the findings and limitations issues, as well as depicting a typology derived from the results. Finally, conclusions and some suggestions for future studies are presented.

\section{Literature review}

Concerning the growing relevance of diversity inside organizations, researchers have examined it through many aspects and lenses. As a consequence, this literature review covers three basic points, namely, the attitudes and perceptions toward diversity, building a positive diversity climate (DC), and diversity organizational discourses. Taken together, the richness of these points provides a broad framework that helps understand diversity scope and magnitude.

\section{Attitudes and perceptions toward diversity}

Overall, the literature suggests the prevalence of different opinions and understandings of diversity (Rabl and Triana, 2014; Riach, 2009; Triana et al., 2012). A blurred scenario also prevails about the organizations' commitment toward removing the obstacles that impede to build an effective diversity culture. In this sense, Pedersen (2010), for example, notes that "It is interesting to look at both what managers talk about and what they do not talk about" (p. 160). To further complicate matters, Pedersen's study revealed that only few managers mention DM and think about the responsibilities related to equal opportunities and fair treatments. Similarly, another study by Tatli (2010) showed that the dominant discourse of diversity tends to be built around business-case arguments and depends on a top-down approach that relies strongly on senior management support. In other words, the findings suggest that the discourse of $\mathrm{DM}$ in the UK is influenced by the US-originated neo-liberal managing diversity perspective, which treats workforce diversity as a commodity that is somewhat subjected to the notion of cost and benefit calculations.

On the other hand, research indicates that people in favor of the values of openness to change and self-transcendence tend to exhibit more positive diversity attitudes (e.g., Sawyerr et al., 2005). Not surprisingly, group identification was regarded as a significant predictor of elaboration and desire to stay in a company when three measures of diversity are contemplated, namely, objective diversity, subjective diversity, and diversity beliefs (van Dick et al., 2008). In order to help remedy this situation, Turnbull et al. (2010) developed and validated an instrument capable of providing an inclusion skills measurement profile and feedback covering seven areas such as diversity sensitivity, integrity with difference, interacting with difference, valuing difference, team inclusion, managing conflict over difference, and embedding inclusion. In a related vein, findings showed that the characteristics of CEOs (i.e., their social values and age) may influence their decisions to implement organizational diversity practices (Ng and Sears, 2012). In other words, the leadership belief about diversity appears to impact the success or failure of any plan related to it. Furthermore, evidence suggests that the adoption of diversity inside organizations obeys predominantly legal compliance imperatives and is usually targeted on group-based categories of disadvantaged. This study rightly warns that

...organizations need to realize that statements of intent or 'being diverse' does not mean effectively dealing with workplace diversity issues in a way to promote equality, fairness and inclusion. They need to develop diversity policies and practices which have accurate 
targets and which are based on well thought out, unambiguous definitions of what is meant by difference and diversity. (Tatli, 2011, p. 250)

Another research focusing on questions institutional and organizational views, practices, and agendas on workplace equality and diversity also in the UK context found a sizable emphasis on profit and sales motives as a justification for DM in the private sector. In contrast, the public sector appeared to be driven "by the principle of social responsibility" (Özbilgin and Tatli, 2011, p. 1241). It is noteworthy a study related to the deontic justice approach. This investigation conducted by Triana et al. (2012) sought to examine personal value for diversity as a moderator of the relationship between perceived discrimination against minorities and judgments about the procedural justice of minorities' treatment by the organization. Results found support for the way people react when they note some sort of discrimination against minorities at work environments. Furthermore, findings suggested that a high personal value for diversity tends to react more strongly in relation of perceived discrimination against women and racial minorities than those with a low personal value for diversity. Results showed that is the personal value that takes to modify the way observers make procedural justice judgments about the treatment of minorities in the workplace. Finally, research also indicates that inconsistent signals on age diversity and age DM practices from a certain organization may prompt it to be regarded as hypocritical to individuals with negative attitudes toward age diversity (Rabl and Triana, 2014).

\section{Building a positive climate}

Assuming that diversity becomes an organizational imperative even though it emanates from humanitarian, social or competition reasons, then, firms should strive to build more receptive environments. Although scholars may disagree about the impact of diversity, there is some evidence that at least in certain organizational settings cultural diversity in groups' composition may be exploited in order to achieve a competitive advantage (Richard et al., 2004). In a related vein, findings showed that race/ethnic heterogeneity was associated with undesirable results such as a low return on income and productivity when an adverse DC prevails, but it was positive when a friendly DC was encouraged. In essence, productivity appeared to be always higher under such a condition (Gonzalez and DeNisi, 2009). Similarly, positive DC is capable of benefiting all employees and such a conclusion refutes any notion of diversity initiatives as a zero-sum game or understanding that DC could be developed at the expense of majority group members (Kaplan et al., 2011). Following the same line of reasoning, Singh and Selvarajan (2013) argue, "As organizations and societies are becoming more diverse, provision of a supportive diversity climate, where individuals can live and work with dignity, has become an absolute necessity [...]" (p. 265).

Actually, the perception of employees in terms of DC tends to lead to a considerable impact on their attitudes and behaviors. Further, evidence suggests that high levels of DC will lead to lowest turnover intentions. Therefore, it is paramount that managers not only strive for communicating the organization's value of diversity to workers, but also work on maintaining ethical practices (Stewart et al., 2011). Research also indicates that by fostering DC on stores one elicits greater customer satisfaction than those ones with less favorable DC, particularly in units where was found highly proservice climates and greater ethnic minority representation (McKay et al., 2011). Importantly, diversity is not going to work if an organization is not able to foster positive attitudes and competence development in its workforce (Groggins and Ryan, 
2013). In sum, building positive DC is essential for embracing heterogeneity and the potential benefits derived from it.

\section{Diversity discourses}

As noted earlier, corporate website statements and electronic reports/documents are intelligent ways of communicating how committed is an organization toward diversity and inclusion. The tone of organizational discourse addressed on such documents help understand if a company is really engaged in providing fair opportunities to minorities and other discriminated groups. Furthermore, the demographic make-up of a company may create the opportunities for or impose barriers to the task of establishing cooperative relationships between teams (Joshi and Jackson, 2003).

The pioneer study of diversity statements by companies across Europe (Point and Singh, 2003) revealed that diversity and related documents were in various locations on corporate websites such as statements on careers, employment pages, statements focusing on corporate profile/business and/or policy/corporate values pages and statements related to corporate social responsibility (CSR) pages. Thirty websites (i.e., $25 \%$ of those who mentioned diversity) did not state precisely the meaning or the scope of diversity to them. Such companies regarded diversity as a universal notion without any explanation. Only few companies provided a clear and precise definition of diversity on their websites. Actually, German and UK companies were the most precise in providing a definition. Nonetheless, when organizations had not presented their practices toward diversity, they had informed at least some initiative concerning anti-discrimination and equal opportunities policies. Of 241 websites surveyed 174 underlined anti-discrimination, equal opportunity or DM policies. Taken together, it was showed on their corporate websites specifications about diversity dimensions such as gender (or sex) in 48\%, culture (45\%), race and ethnicity $(37 \%)$, age (31\%), nationality and country of origin (29\%), and disability (28\%). By and large, this study revealed that a range of themes were associated with diversity.

Another similar study by Singh and Point (2004) found large differences across Europe in terms of web-based promotion of diversity of 241 leading companies in eight European countries, that is, the drivers and stages of diversity management. Evidence showed that the drivers for diversity management were better performance, enhancing corporate reputation, and meeting stakeholder needs. The authors also found six stages of diversity management present in 131 European organizations, namely: diversity as a competitive strategy (32\%), invisible (28\%), DM (19\%), respect for individual $(10 \%)$, equal opportunities (7\%), and avoid discrimination (5\%). Meriläinen et al. (2009), in turn, examined Finnish companies $(n=20)$. Results indicated that just 6 of 20 companies discussed DM in details on their corporate websites. Stated differently, Finnish companies were not appropriately addressing the topic. Research into the UK companies websites (Guerrier and Wilson, 2011) showed that they had sophisticated and comprehensive websites that employed the language of diversity and of the business case. In addition, the messages about diversity were exhibited not just in the diversity pages but also reflected across the careers pages. Findings indicated that young women were used as the "face" of the company while older men were less visible. In sum, the message appealed to the importance of shared values and acceptance of superficial differences. Further, the majority of the companies (about 21) portrayed clearly diversity policy on their websites.

Researchers also investigated the corporate communications about diversity on both the Dutch and the international corporate websites of the ten largest companies in 
the Netherlands (Heres and Benschop, 2010). Authors focused particularly on recruitment/career, CSR sections, and the annual reports of the company for additional information. Data were assessed in terms of the numerical representation of specific categories relating to how diversity and equality were conceptualized (gender/sex, age, ethnicity/race, etc.), and the motives given for diversity management (competitive advantage and recruitment of personnel). In addition, qualitative analysis were carried out in order to find patterns, different meanings given to diversity (management) and equality, the underlying norms, assumptions and omissions in the statements, the reasoning used to legitimate statements, the potential audiences of the communications, and the initiatives related to diversity management. Results showed that eight out of the ten companies mentioned diversity on their Dutch websites, and six made explicit references to equality. However, findings indicated that $100 \%$ of the discussions were regarded as moderate or limited. Importantly, the majority of the references made to diversity and diversity management were placed in the context of the CSR sections of international websites. In other words, just a limited amount of the websites that were studied included statements in their recruitment sections, and when such evidenced was found, the international recruitment sections were clearly more extensive than their Dutch counterparts. At last, findings suggested that diversity management in the Netherlands appeared to be aimed at building an international image and not toward managing individual differences. Corporate websites emphasized the need of creating a competitive advantage in general sense, better understanding and anticipation of different market segments and market changes, and recruiting/retaining the best personnel. Overall, diversity policy may be somewhat hindered in some part of the corporate websites. In general, the pattern is to find no statements related to diversity on the first page of corporate websites. And such a trend clearly suggests that diversity has not been treated as a strategic issue.

\section{Method}

Discourse is regarded as a group of statements which are intertwined to the same discursive base. As such, the discourse is usually grounded on a certain number of statements, which are in turn related to specific conditions capable of being defined (Focault, 1972, cited in Jørgensen and Phillips, 2002, p. 12). Accordingly, the organizational discourse analysis allows outlining how the institutionalization of certain themes is developed. In this sense, it is argued that "...institutions are constituted by the structured collections of texts that exist in a particular field and that produce the social categories and norms that shape the understandings and behaviors of actors" (Phillips, Lawrence, and Hardy, 2004, p. 638).

On the other hand, scholars tend to regard organizations as discursive constructions, given that discourse represents the foundation in which organizational life is built. Such an understanding gives rise to at least three theoretical explanations, namely: (1) the organization is seen as a formed object or entity permeated by certain features and results, which are in turn reflected in discourse; (2) organizations are seen as subject to ongoing transformations that emanate from the content of discourses and patterns of interaction that define, in sum, what they are; (3) and, finally, organizations are perceived as being grounded in actions, as well as urged by social practices and discursive forms (Fairhurst and Putnam, 2004, pp. 5-6).

But it is also argued that the analytical approach of discourses is anchored on the structuralist and poststructuralist linguistic philosophy, given that the access to the 
reality takes place by means of language. In light of this, language give rises to the creation of representations of reality, which are not necessarily by-products of a preexisting reality but they help to construct it. It is important to point out that such reasoning does not preclude reality itself. On the contrary, it is taken for granted that meanings, representations, and physical objects exist, but they are engendered by means of discourse (Jørgensen and Phillips, 2002, pp. 8-9).

Stated differently, when the discourses are coherent and structured, they tend to depict a more unified vision of some aspects of social reality which become, by extension, reified and assumed as true. As a result,

The more reified and taken for granted the social construction, the more difficult or costly it is to enact behaviors not consistent with it, either because it is difficult to conceive of and enact alternatives or because proscribed/prescribed behavior can be defined and connected more clearly to clear, strong sanctions/rewards. When texts contradict each other, or when the relationships among them are less clear, their implications for action are necessarily more negotiable regarding definitions of unacceptable actions and their costs. (Phillips et al., 2004, pp. 644-645).

Paraphrasing Phillips et al. (2004, p. 645), a discourse about diversity and inclusion is supported by other one, which is usually larger in scale and scope. That is, a diversity discourse is highly dependent on the existence of other discourse that approaches the value of human resources. Therefore, without the existence of the latter would be difficult to conceive a specific discourse concerning diversity.

Thus, this study focuses on how these companies are addressing the themes of diversity, inclusion and discrimination through their organizational discourses ${ }^{\mathbf{1}}$. More specifically, it draws exclusively on the statements and corporative documents posted on their websites. After all, corporate websites constitute a germane mean of corporate communications whereby one may identify values and beliefs embraced by organizations. Taken as a whole, they shape an organizational discourse. Thus, the websites show not only important aesthetics aspects of organizations, but also discursive ones. Consequently, it is expected that they depict similar approach in relation to the topics aforementioned due to their relevance. By analyzing their content one may find which topics are indeed of paramount importance to organizations. Furthermore, Cole and Salimath (2013) suggest that "[...] By utilizing visible symbolic cues, such as diversity management programs or diversity statements, organizations construct perceptions of legitimacy among key stakeholders. [...]" (p. 153).

\section{Data and procedure}

As previously pointed out, the goal of examining the best companies to work for list ${ }^{2}$ derives essentially from the fact that these organizations are seen as top-tier firms. As such, they constitute the best employers of the country. In other words, to be part of such list means practically to win an "Oscar" of organizational performance and corporate branding. The ranking per se usually depicts relevant data about organizations' policies, business sectors, and human resources strategies whereby one can elicit interesting insights and findings. According to the GPTW Institute, a great workplace can be measured:

- by the quality of the relationship between employees and management;

- the relationship between employees and their jobs/company; and

- the relationship between employees and other employees.

This investigation will not address the GPTW method. In fact, there are enough reasons to believe that the organizations had strived to adhere to that when they 
voluntarily accepted to pursue that business award. Importantly, the GPTW Institute lists have been published in 40 different countries and it is a signal of the relevance. Presumably, firms operating in Brazil, as should equally do their branches and the companies operating in other nations where the institute is present, have strived to be part of those rankings.

In addition, throughout the process of labeling codes I took into account previous investigations' classifications. Thus, the raw data (statements and document texts) were carefully read, analyzed and classified, to a large extent, according to the themes, topics, and issues identified in earlier studies. Whenever was possible comparisons were done. Afterward, the data were checked and rechecked several times. At last, the results were compared and contrasted until a saturation point was reached so as to assure a reliable outcome. Importantly, in order to assure reliability, two independent researchers checked the classification and disagreements were resolved by discussion.

\section{Sample}

Of the 130 companies awarded by GPTW-Época 2014's list, 57 (43.8\%) somehow matched the criteria aforementioned, that is, they posted some discursive relatedmaterial on their corporate websites worthy of analysis. At first glance, this result may be considered somewhat disappointing given the relevance of such group of organizations. The general data were collected on September 2014 in accordance with the following procedure: (1) by probing specific icons and when it was unfeasible (2) by using search engines in order to find any material (statement) related to the keywords under scrutiny.

The business sectors of the sample were quite varied such as: chemical, hotel and restaurants, beverage and foods, mining, biotechnology and pharmaceutical, outsourcing services/call center, financial services/insurance, metal industry, technology information, energy distribution, aerospace, banking, machines and equipments, consumer goods, motorcycle, health services, automotive, agriculture, forestry and fish farming, industrial and engineer services, silicones and wood products. Taken together, the sample was made up of 35 (61.4\%) industries, 21 (36.8\%) services organizations and just 1 health services firm (1.8\%). Otherwise, the sample was composed of 34 (61.4\%) larger organizations, 19 (33.3\%) middle multinational companies and 3 (5.3\%) middle national firms. The majority of their headquarters were located in the Southeast area (89.5\%) of the country, especially in the state of São Paulo (84.2\%). On the whole, these companies employed 445,390 workers.

\section{Results}

\section{Number of clicks necessary to achieve a page/document}

The first endeavor was to describe the path to get access to the major contents. In this regard, Table 1 presents a synthesis around some common topics. Note that only 14 companies $(24.6 \%)$ of the sample offered a direct link to the themes of the investigation. That is, it was found news, sustainability, and about us as the major subjects (icons). Surprisingly, this study found no evidence that an organization had a direct link to diversity topic in the menu bars. Notwithstanding diversity, inclusion, and discrimination are themes strongly intertwined with other topics of corporate life at least in the discursive level. On the other hand, it is noteworthy that news icon - located through searching engines - is the most important alternative to achieve such pages. It 
suggests that the majority of organizations are not exploring such themes on their websites as they should. To a large extent, it indicates that diversity-related issues are not treated as core themes or discursive constructions through corporate websites. Just one organization placed diversity linked to principles and values:

Principles and Values

Over ...years of history in the world and 70 in Brazil, we built one way of acting in a daily basis, which was summarized by the following principles and values:

[...].

Diversity

We want a workforce as diversified as the markets we serve, and create opportunities to achieve this goal. (firm 40, food industry) ${ }^{3}$

However, two organizations posted the core themes on general information about themselves as follows:

[The name of the company]

Our People \& Culture

Wherever we are [company name] workers share the same essential cultural characteristics.

We are the same at work. We enjoy the company of our colleagues and we value honesty and transparency. Appearance and origin are not important for us: ideas and doing the right thing are. We reject discrimination, inequality and promote diversity in all its forms.

We proudly, passionately and actively encourage [company name] and our industry to reflect and include the society they serve. (firm 42, technology and information)

[The name of the company]

Building our culture. Our culture represents the way we work together with energy, passion, and respect for people. It is related to the involvement, open dialogue, and "feedback." It emphasizes diversity, teamwork and leadership. It is how we create trust, customer focus and promote change.

[...]

Diversity. We are unique, each with its particular history and their different experiences. We seek a fair, equitable, and respectful treatment. We also have the common goal to serve our customers in order to generate gains for all.

We are turning all the differences in benefits. There is great strength in diversity. This helps to increase our productivity, cooperation, and innovation and helps us to build stronger relationships with customers and local and global partners. (firm 33, automotive industry)

As regard to related topics available at two clicks in the websites, the principal icons to get access to the core themes were careers (3) and about (2 companies). Therefore, just 6 diversity icons $(24.0 \%)$ were found under such criteria $(n=25)$. This result suggests that companies have not placed enough relevance for the topics under scrutiny. By contrast, the best results were identified at three or more clicks. That is, 10 of 18 organizations (55.6\%) had one and/or more of the examined subjects available to consult. Obviously, it indicates that researchers and cybercitizens have considerable work in order to find and read some organizational discourse (statement or document). Under this alternative, however, the icons are slightly more salient than previous procedures.

It is worth pointing out that just one organization had the initiative to place a video about diversity and inclusion on its website: "Learn how ... is harnessing the 
power of Inclusion and Diversity with its people, customers, and community" (firm 39, technology and information, original text). Taken as a whole, therefore, the findings suggest that diversity, inclusion, and discrimination are seen as either secondary themes or almost irrelevant ones by the majority of the best organizations to work for in Brazil confirming thus other research related to this subject (e.g., Jabbour et al., 2011; Vasconcelos, $2016 \mathrm{a}$, b, forthcoming).

Table 1. Topics and total of mentions

\begin{tabular}{|c|c|c|c|c|}
\hline \multicolumn{5}{|c|}{ Related Topics Available at Just One Click in The Websites* $(n=14)$} \\
\hline $\begin{array}{l}\text { About us } \\
(2)\end{array}$ & $\begin{array}{l}\text { Code of Conduct } \\
\text { (1) }\end{array}$ & $\begin{array}{ll}\text { News } & \\
& \end{array}$ & $\begin{array}{l}\text { Sustainability and } \\
\text { Report about } * * \\
(3)\end{array}$ & $\begin{array}{l}\text { Work for Us } \\
\text { (1) }\end{array}$ \\
\hline $\begin{array}{l}\text { Careers/Talent } \\
\text { Development } \\
\text { (1) } \\
\text { Careers / } \\
\text { Diversity } \\
\text { (1) } \\
\text { Careers/Our People and } \\
\text { Culture-Diversity } \\
\text { (1) }\end{array}$ & $\begin{array}{l}\text { Sustainability/ } \\
\text { Introduction } \\
\text { (1) } \\
\text { Sustainability/ } \\
\text { Social Balance } \\
\text { (1) }\end{array}$ & $\begin{array}{l}\text { Company/ } \\
\text { Ethical Code } \\
\text { (1) } \\
\text { About .../ Corporate } \\
\text { Principles } \\
\text { (1) } \\
\text { Our Principles/ } \\
\text { Code of Ethics } \\
\text { (1) } \\
\text { Industries/ Code of } \\
\text { Conduct } \\
\text { (1) } \\
\text { About.../ Corporate } \\
\text { Principles } \\
\text { (1) }\end{array}$ & $\begin{array}{l}\text { Name of the } \\
\text { Company/ } \\
\text { Social Responsibility } \\
\text { (1) } \\
\text { Our Company/ } \\
\text { Our People } \\
\text { (1) } \\
\text { About.../ Diversity } \\
\text { (1) } \\
\text { About.../ Diversity } \\
\text { (1) }\end{array}$ & $\begin{array}{l}\text { People/ } \\
\text { Work at... } \\
\text { (1) }\end{array}$ \\
\hline $\begin{array}{l}\text { Institutional/ } \\
\text { Mission, Vision, and Values } \\
\text { (1) } \\
\text { Who we are/ Vision, and } \\
\text { Values } \\
\text { (1) } \\
\text { About us/ } \\
\text { Our Mission } \\
(1)\end{array}$ & $\begin{array}{l}\text { Work at.../ } \\
\text { Diversity } \\
\text { (1) } \\
\text { Join to.../ } \\
\text { Inclusion and } \\
\text { Handicapped } \\
\text { Program } \\
\text { (1) }\end{array}$ & $\begin{array}{l}\text { Purpose and People } \\
\text { / Diversity \& } \\
\text { Inclusion } \\
\text { (1) }\end{array}$ & $\begin{array}{l}\text { Social Responsibility/ } \\
\text { Code of Ethics } \\
\text { (PDF) } \\
\text { (1) } \\
\text { Social Responsibility } \\
\text { /Core Themes of } \\
\text { Social Responsibility } \\
\text { (1) }\end{array}$ & $\begin{array}{l}\text { Code of Conduct and } \\
\text { Ethics / } \\
\text { Social Responsibility } \\
\text { (1) }\end{array}$ \\
\hline $\begin{array}{l}\text { Corporate } \\
\text { Information/Name of the } \\
\text { Company } \\
\text { (1) }\end{array}$ & & & & \\
\hline \multicolumn{5}{|c|}{ Related Topics Available at Three Clicks in The Websites $(n=18)$} \\
\hline $\begin{array}{l}\text { Our Company/ Corporation } \\
\text { Information/ Corporative } \\
\text { Responsibility/ } \\
\text { Diversity } \\
\text { (1) } \\
\text { About.../ } \\
\text { Corporate Responsibility/ } \\
\text { Diversity \& Inclusion } \\
\text { (1) }\end{array}$ & $\begin{array}{l}\text { Recruitment \& } \\
\text { Careers/Why } \\
\text { choose ...?/ } \\
\text { Diversity } \\
\text { (1) } \\
\text { Work with us / } \\
\text { Name The } \\
\text { Company - } \\
\text { Introduction to } \\
\text { Career } \\
\text { (1) } \\
\text { About... } \\
\text { /Careers/Life at ... } \\
\text { (1) }\end{array}$ & $\begin{array}{l}\text { The.../ } \\
\text { People \& } \\
\text { Management/Social } \\
\text { Inclusion Program } \\
\text { (1) }\end{array}$ & $\begin{array}{l}\text { Career/Diversity/ } \\
\text { Inclusion } \\
\text { (1) } \\
\text { Careers/Why.../ } \\
\text { Diversity and Inclusion } \\
\text { (1) } \\
\text { Careers / Why to Work } \\
\text { Here / Diversity } \\
\text { (1) }\end{array}$ & $\begin{array}{l}\text { Responsibility/ } \\
\text { Our People/ } \\
\text { Diversity \& Inclusion } \\
\text { (1) } \\
\text { Corporate } \\
\text { Responsibility/More } \\
\text { about People/ } \\
\text { Developing Our } \\
\text { People } \\
\text { (1) }\end{array}$ \\
\hline $\begin{array}{l}\text { Press } \\
\text { Room/Releases/Diversity: }\end{array}$ & $\begin{array}{l}\text { About.../ } \\
\text { Work for Us/ }\end{array}$ & $\begin{array}{l}\text { Sustainability/ } \\
\text { Vision \& Strategy/ }\end{array}$ & $\begin{array}{l}\text { Name the } \\
\text { company/Who we }\end{array}$ & $\begin{array}{l}\text { Our Company / About } \\
\text { us/ }\end{array}$ \\
\hline
\end{tabular}




\begin{tabular}{|l|l|l|l|l|}
\hline $\begin{array}{l}\text { watchword in successful } \\
\text { business } \\
(1)\end{array}$ & $\begin{array}{l}\text { Diversity } \\
(1)\end{array}$ & $\begin{array}{l}\text { Employee } \\
\text { Engagement } \\
(1)\end{array}$ & $\begin{array}{l}\text { are/Code of Ethics } \\
(1)\end{array}$ & $\begin{array}{l}\text { Our Values } \\
(1) \\
\text { About.../ } \\
\text { Company in the } \\
\text { world/ Values } \\
(1)\end{array}$ \\
\hline $\begin{array}{l}\text { About Cisco/Inclusion and } \\
\begin{array}{l}\text { Diversity/About Us } \\
(1)\end{array}\end{array}$ & & & & \\
\hline
\end{tabular}

Notes:

Source: Author's own findings.

* It refers to the number of clicks necessary to achieve a useful content related to diversity, inclusion or discrimination.

** Multiple alternatives were accepted.

\section{Mention of the major themes}

Concerning the major themes of this investigation, the findings revealed that diversity (54.4\%) was the most cited on corporate discourses (see Table 2). Put another way, it was found that almost the entire sample mentioned someway the word diversity in their statements/documents. Such a result suggests that diversity has been gradually incorporated into Brazilian organizational discourses. Discrimination, in turn, was cited for less than half of the sample companies. By and large, this outcome indicates that organizations have not made convincing cases against discrimination as they should. Therefore, this study also confirms the results of previous investigations (e.g., Cepellos \& Tonelli, 2017; Vasconcelos, 2012, 2016a, b, forthcoming). In a similar manner, inclusion initiatives have been poorly addressed. Overall, few organizations reported what they were doing in this particular issue. For example, a company exhibited a statement related to its initiative, particularly toward enhancing female worker opportunities:

In 2013 some $84 \%$ of all the professionals we hired reflected our international footprint and $31 \%$ of those were women. In other words, more representative of the world in which we live, but still requiring attention.

Diversity is especially important at the senior level to ensure ... continues to 'stay the course' through turbulent and fast-changing market conditions. It's why the percentage of women executives in our organization is increasing. Some $11 \%$ of our executives are now female (a steady rise since...).

Meanwhile, we're recruiting far more non-Europeans into senior executive positions; $75 \%$ of all executive hires in 2013. In fact, we are hiring more outside talent into ... altogether reflective of our need to be in closer step with the global markets we serve.

To keep building a diverse company we need to continue making ... an attractive place to work for a highly sought-after global talent pool. (firm 14, food industry)

Another company revealed to be equally concerned with women representation within its workforce. Although such firm referred to another of its served markets it is worth mentioning.

The Women's Leadership Development Initiative, which has increased representation of women in leadership positions; 53\% of [name of the company]'s U.S. managers, including executives, are women. (firm 47, hotels, resorts, and restaurants)

Table 2. Summary of findings

\begin{tabular}{|c|c|c|}
\hline Themes & $\begin{array}{c}\text { Frequency } \\
(\mathbf{n = 5 6 )}\end{array}$ & $\mathbf{\%}$ \\
\hline Diversity & 49 & 54.4 \\
\hline Inclusion & 21 & 23.3 \\
\hline Discrimination & 17 & 18.9 \\
\hline Prejudice & 3 & 3.3 \\
\hline
\end{tabular}




\begin{tabular}{|c|c|c|}
\hline Total & 90 & 100.0 \\
\hline
\end{tabular}

Note: Multiple alternatives were accepted.

The findings about themes showed other interesting aspects that are noteworthy (Table 3). For instance, the concern of providing equal opportunities to all groups was identified in 17 statements. On the surface, it can be regarded as a modest result; nonetheless, it also denotes some advancement toward a very sensitive issue. However, by communicating the initiative of giving room to disabled workers is, to some degree, unnecessary taking into account that this is an imperative of law. In addition, the same reasoning can be applied to young apprenticeship programs. Following an international trend and consistent with the literature (Fasterling and Demuijnck, 2013; Mena et al., 2010; Murphy and Vives, 2013), some companies demonstrated to be concerned to respect human rights.

Importantly, it was found some evidence linking the core themes under investigation with some sort of fairness organizational initiative. In theoretical terms, such an approach is grounded on discrimination-and-fairness perspective (Ely and Thomas, 2001). Thus, companies inspired by such a view claim that

[We] cherish for a favorable and fair environment where respect prevails. For this, we established commitments related to diversity, justice, and equality in the relationships between our employees and other stakeholders. (firm 18, biotechnology and Pharmaceutical, emphasis added)

... is committed to providing equal employment opportunities. This means that we must treat our coworkers and ... applicants fairly and never engage in any form of illegal discrimination. In our hiring decisions (such as recruitment, hiring, training, salary, and promotion) we follow all applicable laws and do not discriminate against people based on race, color, sex, age, national origin, religion, sexual orientation, gender identity and expression, marital status, citizenship, disability, veteran status, status of HIV/AIDS or any other legally protected aspect (firm 28, consumer goods industry, emphasis added).

Table 3. Summary of other findings

\begin{tabular}{|l|c|c|}
\hline Mentioned themes & Frequency & \% \\
\hline Equal opportunities & 17 & 38.6 \\
\hline Disabled workers & 15 & 34.1 \\
\hline Human Rights & 6 & 13.6 \\
\hline Fairness initiative & 3 & 6.8 \\
\hline Precise definition of diversity & 2 & 4.5 \\
\hline Young apprenticeship & 1 & 2.4 \\
\hline Total & 44 & 100.0 \\
\hline
\end{tabular}

Source: Author's own findings.

The meaning of diversity seems to be a blurred topic or perhaps a taboo for the overwhelming majority of the sample, given that just two companies strived for providing a clear definition about it. One of those companies posted a PDF file on its website. In a sense, it placed diversity as a valuable aspect, which someway reinforced corporate values and mission. Meanwhile, the other company addressed diversity as a source of richness by recognizing all potential and capabilities derived from it.

Diversity means embracing different styles, behaviors and mindsets, while remaining true to ... values and mission. There are so many aspects of diversity that are important: age, nationality, culture, ethnic background, gender, religion, to name a few. Just as strategy is all about making choices, we need to focus our resources on specific areas in diversity. (firm 
Diversity at ... is ...

... a set of differences and similarities that define each of us as unique individuals. At ... diversity is what makes us richer, regardless of race, religion, personal characteristics, physical characteristics, economic profile, opinions, perspectives, sexual orientation, educational background, nationality, age, physical disabilities, among others. (firm 44, financial and insurances services)

Overall, these results suggest that companies could be more creative by enriching their discourses with other pertinent particularities. In this way, they would show a firm strong commitment to the cause of diversity.

\section{Aesthetical aspect}

With reference to this dimension, evidence showed that 28 (49.1\%) of the sample employed some sort of photography resource. Some companies inserted many photos within their documents/pages with the clear goal of showing that they were engendering workforce diversity. In some cases, the same strategy was implemented in order to signal that they were employing disabled workers, regardless of such policy simply conforms to the law. It is worth pointing out that two companies exhibited the photos of all members of their staffs. Overall, such initiatives are very positive, yet it must be acknowledged that the younger generations' pictures prevailed.

\section{Words and associated constructs}

The results also showed that diversity and inclusion can be regarded as multidimensional topics because they both encompass a sizable number of aspects and features (sub-themes). In fact, the words and statements - i.e., elements of organizational discourse - cited below corroborate such a perception.

- Held values. Some companies (12) vehemently emphasize the importance they attribute to diversity and inclusion as part of their corporate values. Thus, the respect for individual characteristics is generally pointed out. For example, a certain company remarked: "all valued, all included, all performing their best" (firm 28, consumer goods industry). Another organization reported that "Diversity and inclusion are closely tied to our core values and our strategic business goals, so they are embedded into every facet of our business" (firm 47, hotels, resorts, and restaurants).

- Leadership. Nine firms addressed their efforts in relation to leadership aspect. Some companies reached the stage of reporting the programs they were putting into practice toward opening more opportunities to women, particularly to increase their share in managerial positions and the workforce. In some cases, such initiative was referred to as inclusive leadership. In this light, a company stated that " $A$ more balanced ... leadership group (in terms of gender, nationality and background) will improve our decision making process as well as the implementation of ...'s strategy [...]" (firm 14, food industry). By the same token, a biotechnology and pharmaceutical industry made clear its senior leadership commitment to diversity. In fact, some researchers have argued about the need of such involvement in order to reach better results (Calo, 2008; Cox and Blake, 1991; Crampton and Hodge, 2007; Demuijnck, 2009; Gelfand et al., 2005; Linnehan et al., 2006; Vasconcelos, 2012).

- Culture. Seven organizations mentioned a linkage between culture and diversity/inclusion. As diversity and inclusion have increasingly gained impetus, 
more companies mention these issues as part of their organizational cultures as well. In fact, it appears that some firms are proud to "sell" an inclusive culture by means of their discourses. For instance, a company suggested some relevant benefits derived from it, "An inclusive culture where diverse talents can flourish is also critical to attracting and retaining the best people in the right places to take our business forward" (firm 7, biotechnology and pharmaceutical industry). Another company claimed that "[the name of the firm] believes that fostering an inclusive culture that embraces differences will help to create a more diverse workforce which will drive a high performance organization achieving its business and strategic goals, especially in view of ...'s focus on further internationalization, innovation and sustainability [...]" (firm 14, food industry). Highlighting such corporate value, a company addressed that "[...] No organization can afford to dismiss the potential benefits of having a diverse and inclusive culture. So for ... is an ongoing and essential business imperative to build an inclusive and diverse organization [...]" (firm 39, technology and information industry).

- Sustainability. Surprisingly, the findings also revealed some connection between sustainability and diversity (only 4 companies). Research has been indeed paid scant attention to this linkage (e.g., Wiernik et al., 2013, for age and environment). Nevertheless, it appeared on the centerpiece of strategic issues like the following example: "Sustainability in [name of the company] is synonymous with innovation and is part of the strategic planning of the company in product launches, as well as improvements in internal processes ... Our employees are encouraged to make their decisions considering the respect for the environment, diversity, ethics and transparency" (firm 10, beverage and foods industry). Another company mentioned it as a component of social development by arguing "...respect for diversity of ideas, cultures, profiles, gender, and age of its employees" (firm 34, electronic industry). It is worth emphasizing that two companies cited diversity within specific sustainability documents.

On the other hand, the word "diversity" was also present in some code of ethics (see Table 1). For some organizations such kind of document works like a starting point, so to speak, to gain ground on diversity/inclusion realm. The findings showed two cases of statements related to equal opportunities, non-discrimination, and diversity. For example, a mining company remarked: "Our relations are based on the principle of equal job opportunity for all people regardless of race, social class, nationality, religion, disability, gender, sexual orientation, political affiliation or any other form of diversity" (firm 56). Another large company noted, "The pursuit of diversity is a direct consequence of the search for innovation. [...]. So it is not permitted discrimination by sex, color, religion, age, sexual preference, physical or mental disability" (firm 10, beverage and foods industry).

Obviously, the data revealed consistent cues of diversity concerns linked with business goals. But only one CEO (food industry) made clear his position in a PDF file about diversity posted in the company website where he claimed

In order to deliver on our strategic goals, we need more diversity in ... This is a prerequisite for being successful with innovation, internationalization and several other of our ambitions. Bottom line we mean diversity with the embracement of different styles, behaviors and mindsets, though all fitting with ...'s values and mission [...].

This statement suggests that at least in this organization diversity is also seen as an instrumental value. 


\section{Other discourse contents}

Findings indicated that companies were also concerned with other related issues in their discourses. For example, Table 4 exhibits other sub-themes which emerged from the investigation and that were worthy of analysis as well. In this way, companies demonstrated to be committed to avoiding any form of discrimination in their relationships with employees (20.7\%). In doing so, they were certainly urged by the imperatives of law. After all, it is always undesirable to the business corporate image to get involved in some sort of unfair treatment or bias. In another vein, firms showed to be fully engaged to take advantage of their diversity policies such as getting competitive advantage (19.0\%), obtaining more creativity and innovation capabilities (17.2\%), and improving business and/or personnel results (13.8\%). Illustrative examples are the following statements:

We believe that a workforce that reflects the global environment in which we operate will help us deliver top performance in a rapidly changing marketplace and enable us to attain greater business success. (firm 37, food and beverage industry)

Our results demonstrate that the collaboration of different cultures, ideas, and perspectives is an organizational asset and yields greater creativity and innovation. Global diversity and inclusion are business critical to the current and long-term success of ... (firm 48, technology information industry)

...believes that diversity is essential for better business results, since it generates an important competitive advantage (creating and discussion of new visions, new ideas, and new products) and a good working environment for the company. Companies that are open to new thoughts know how to develop solutions that meet the needs and interests of employees, customers, and society in general. (firm 3, metal industry)

Our ... program aims to accelerate the development of our leadership culture and talent pipeline through sharing diversity of thought and experience. The program... consisting of 60 coaching pairs of individuals from different leadership levels, functional areas and geographies. (firm 7, biotechnology and pharmaceutical industry)

[...] The company permanently believes that 'success comes much more from the sum of the differences than the sum of equalities.' [...]. (firm 10, beverage and foods industry).

Table 4. Other sub-themes

\begin{tabular}{|l|c|c|}
\hline Issues & Frequency (N= 56) & \% \\
\hline Avoid discrimination & 12 & 20.7 \\
\hline Competitive advantage & 11 & 19.0 \\
\hline Creativity and innovation & 10 & 17.2 \\
\hline Improved business and/or personnel results & 8 & 13.8 \\
\hline Recruiting and personnel selection & 6 & 10.3 \\
\hline Social responsibility & 5 & 8.6 \\
\hline Relationship with stakeholders & 3 & 5.2 \\
\hline Training/Development & 2 & 3.4 \\
\hline Better understand the market & 1 & 1.7 \\
\hline Total & 58 & 100.0 \\
\hline
\end{tabular}

Note: Multiple alternatives were accepted.

Source: Author's own findings.

The findings also indicated some level of concern particularly related to broader diversity policies, i.e., recruiting and personnel selection (10.3\%) and social responsibility (8.6\%). The former sub-theme is addressed in a straightforward way as 
the examples below show. Whereas the latter one is, by and large, emphasized within the context of social responsibility policy (an exception is the last statement). Furthermore, it is germane to note that CSR theory has been associated with diversity, inclusion, and discrimination constructs (e.g., Armstrong et al., 2010; Bjerregaard and Lauring, 2013; Demuijnck, 2009; Olsen and Martins, 2012; Özbilgin and Tatli, 2011; Point and Singh, 2003; Roberson and Park, 2007).

The Organization believes that diversity creates a healthier and more productive work environment for everyone. One way of valuing diversity is hiring people with disabilities. (firm 9, financial services)

Recruit, promote, and support the professional development of a globally diverse workforce. (firm 22, consumer goods industry)

[...] Through inclusion program, we seek much more than the social inclusion of people with disabilities. We mainly work in order to provide learning and training, helping in professional development of these people. (firm 26, motorcycle industry)

Diversity and social responsibility must be more than concepts. It is important to live them in practice and ... gives evidence of this concern with the implementation of the special program for trainees, who hired ... 14 disabled workers... (firm 32, health services)

In a lesser degree, evidence also indicated that the existence of other sub-themes such as the need of establishing relationship with stakeholders (5.2\%), training/development (3.4\%), and the importance of better understand the market $(1.7 \%)$. Taken as a whole, they reassure the multifaceted nature of diversity by connecting it with other dimensions of organizational life.

\section{Results from typologies}

The data allowed me to do some analysis (coding) in terms of stages of DM. Thus, I first used an insightful taxonomy employed by Singh and Point (2004) that portrays all possible dimensions. Overall, it covered six stages, namely:

1. Invisible. This category considers the companies that do not mention diversity or equal opportunities on their websites and, accordingly, it is unclear what the company intend to do.

2. Avoid discrimination. It refers to companies that are committed to not allowing that discrimination takes place. As a result, they usually use defensive language in their statements without emphasizing the positive side derived from equal opportunities.

3. Equal opportunities. It encompasses the organizations that clearly indicate to be involved in promoting equal opportunities or treating all employees equally without mentioning diversity or competitive advantage.

4. Respect for the individual/capabilities. Basically, it indicates that differences would be respected. In this stance, the organization usually promised to provide the right kind of work environment by following the United Nations Human Rights and 'Capabilities' philosophy.

5. Diversity management. This refers to companies that support and value diversity. Unlike Singh and Point (2004), it was considered all companies that mentioned diversity regardless of arguing why it was important to them. However, DM has been associated with business benefits of managing a diverse workforce, that is, the demographic characteristics (Olsen and Martins, 2012; Syed and Kramar, 2009) or, as put by Kulik (2014), a diversity management system necessarily covers diversity paradigms, polices, programs, practices, and climate. As a consequence, an 
alternative path was chosen by coding all material that mentioned diversity as part of conscious DM effort no matter how important it was for a company. Such a decision lies on the fact that diversity is nowadays a recognized managerial task.

6. Diversity as competitive advantage. It embraces all companies that search for ways to take advantage of diversity in order to improve their business results.

However, it was unfeasible to match all firms in a specific category without disregarding other equally relevant aspects given the nature of organizational discourses gleaned. Unlike Singh and Point (2004), a different approach was pursued here. More specifically, all discursive elements were taken into account and classified not as stages of diversity, but as explicit dimensions of DM. In this way, findings indicated that 51 ( $91.1 \%$ of the sample) companies cited something related to DM in their organizational discourses; 25 (44.6\%) made some reference about getting competitive advantage; 13 (25\%) mentioned efforts toward providing equal opportunities; 13 (25.0\%) showed to be concerned about avoiding discrimination; and 4 (7.1\%) refereed to the human rights. Importantly, this study found no evidence of invisible dimension. The results suggested that a scenario of diversity learning was taking place at least in the discursive stance. Another indicative of such a perception was the fact that $26(46.4 \%)$ organizations refereed to two of dimensions aforementioned, $18(32.1 \%)$ mentioned only one, 10 (17.9\%) exhibited more concern by approaching three dimensions and just $2(3.6 \%)$ refereed to four aspects (Figure 1 portrays the results).

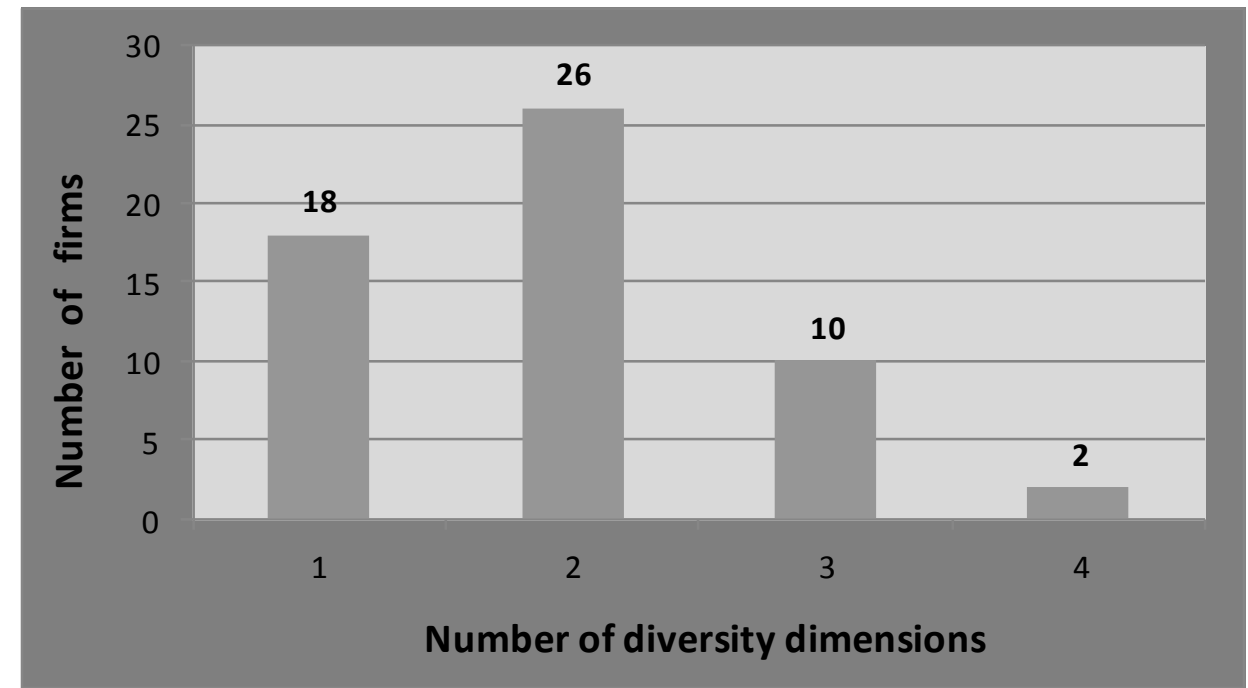

Figure 1. Types of diversity dimensions adopted by organizations $(n=56)$

Source: Author's own findings.

At last, it was possible to assess the results on the face of the terminal, instrumental, and dual values. As noted earlier, theory refers to terminal values as desirable end states whose organizations in this case strive to achieve, whereas diversity as an instrumental value focuses on achieving business success. Nonetheless, dual values cover both perspectives (Rokeach, 1973, cited in Olsen and Martins, 2012). Thus, findings showed that instrumental values prevailed in most organizations (41 or $73.2 \%$ ) In other words, mostly companies expected to accomplish better results by means of diversity. In contrast, terminal values were pursued by 9 companies $(16.1 \%)$ of the sample. In essence, these firms expressed somehow their commitment to valuing and/or promoting diversity. It is astonishing that the dual values were associated with 
only a few organizations (6 or 10.7\%). Thus, it appears that even here the discursive resource remains underutilized.

\section{Discussion}

By drawing on a different methodological approach, this investigation corroborates somewhat the findings of previous studies covering Brazilian context, which indicated the huge difficulty to incorporate diversity-related themes (e.g., Fleury, 1999, 2000; Irigaray and Vergara, 2011; Jabbour et al., 2011; Nóbrega et al., 2014; Pereira et al., 2012; Santos et al., 2008; Saraiva and Irigaray, 2009). Put another way, barely 57 (43.8\%) of the 130 companies awarded by GPTW-Época 2014's list showed some interest in providing a discourse toward diversity/inclusion issues in their websites. Such a result is very disappointing given that the diversity theme has been around since 1990s (Fleury, 1999). Moreover, this study gleaned evidence that no more than 31 firms (54.4\% of the sample) depicted a compelling or somewhat acceptable diversity discourse (i.e., an indication that this issue has been addressed, yet it requires additional measures).

Reinforcing such a view, it must be remarked that, except an information technology company (firm 27) and a food company (firm 14), the rest of the sample did not even offer a complete workforce demographic statistics in their websites. In fact, such data were usually ruled out by organizations, yet they would certainly provide a demographic make-up of the organization. In addition, such information would indicate firms' level of commitment to this theme. The few initiatives were predominantly gender-driven or focused on nationality features, that is, they reported the actions carried out in order to get a right mix. Regrettably, there was no evidence of any measure toward giving room to, for example, Blacks and/or reducing ageism. Even though they referred to their efforts against discrimination, particularly in the codes of conduct or ethics, ideally a demographic statistics should be provided, for example, by informing how many Blacks, Indigenous, older employees, foreign workers, LGBT members, disabled workers, among other groups, were employed. However, what really matters to build a robust organizational discourse is the capability of providing compelling evidence about what they are indeed doing. Therefore, it is ineffective to depict only generic statements like the following examples:

Believing that respect for diversity is one of the main qualities of our culture ... created the Program for Social Inclusion.

...we seek to admit handicapped professionals to our workforce. (firm 4, beverage and food industry)

We are truly dedicated to an inclusive environment where diversity is understood and welcome. (firm 21, machines and equipments industry)

We are passionate about diversity and inclusion, respect individual differences and characteristics, making these new ingredients for business success. And to attract, retain and develop diverse talent is part of this strategy. (firm 24, food industry).

The ...'s concern about people begins at home, in their plants and headquarter, with the appreciation of the diversity of ideas, cultures, shapes, genders, and age of its employees. (firm 34, electronic industry)

Simply put, companies should clearly present the result of their diversity and inclusion policies on their websites, as well as stating their goals related to it. Even a 
diversity index was a measure undertaken by only one organization (firm 14, food industry). And it is a vital procedure to nurture diversity inside organizations. Overall, the findings indicated that the simple exhibition of a specific and well-elaborated diversity/inclusion webpage was not a priority for most organizations. In this sense, evidence revealed that a certain biotechnology and pharmaceutical - awarded as one of the top DiversityInc ${ }^{\circledR}$ - did not have an icon about diversity on its webpage. Apparently, the majority of organizations employ the diversity discourse aiming to show that they comply with legal requirements related to assuring a certain number of job positions for disabled workers. In addition, organizational statements tend to be vague, that is, they rarely inform what companies expect in terms of diversity goals. Similarly, it is also absolutely surprising, at this juncture, that CEOs do not show a clear engagement in building multicultural organizations through corporate websites discourses.

In terms of theoretical contribution, Figure 2 presents a taxonomy based on the results. Although this procedure is grounded on a subjective and idiosyncratic understanding, yet it emerges naturally from the data of organizations' websites. In this sense, this taxonomy derives from firms' similar statements, interests, contents, kinds of documents, and relevance attributed to the topics of diversity, inclusion, and discrimination. Such a conceptualization helps to paint a picture about how firms are indeed dealing with the variables under scrutiny in their organizational discourses. Therefore, four quadrants are envisaged, namely: engaged, adaptation, cynicism and unconcern. Each type of organization and its major features are described below.

- Unconcern. These organizations do not show any sort of DM statement on their websites. As such, they appear to be completely disengaged from diversity issues at least in the discursive stance. Regrettably, the unconcern category was the largest of the 130 best companies to work for sample (56.1\%). Such a result was very discouraging given the characteristics of the organizations under scrutiny (i.e., nationally acknowledged as praiseworthy companies in terms of HR policies). Either way, the companies that fitted into this profile employed 206,633 workers. This group comprised thirty-five large companies, eleven middle multinational and twenty-seven middle domestic ones. The higher employer of this typology employed 43,911 workers (a traditional food services firm), whereas the lower one employed just 107 (a technology information organization). Overall, companies that embraced the unconcern frame employed, on average, 2,831 employees. Unconcern type of organizations was spread out into a myriad of business sectors; nonetheless, they were somewhat salient in information technology (12), retail (11), education (6), financial services/ insurance (6), health services (5), automotive (4), biotechnology and pharmaceutical (3), and telecommunications (3).

- Adaptation. This dimension involves organizations that are striving to put into practice DM policies even though under the title of corporate responsibility, mission statement or other-related documents. Evidence suggested that organizations that operate under the adaptation frame are trying to find the better way to address the diversity cause. Nonetheless, it seems that such a topic is somewhat blurred to them. Such organizations represented the second largest group of this taxonomy, that is, $26.9 \%$ of the sample. Overall, companies that fitted into this profile employed 269,610 workers. This group comprised nineteen large companies, thirteen middle multinational ones and just three middle domestic ones. Moreover, the higher employer of this typology employed 84,231 workers (actually, two companies employed a workforce of more than 80,000 workers take part if this quadrant), whereas the lower one employed just 123. The companies that embraced the 
adaptation conceptual frame employ, on average, 7,703 employees. Findings showed that a wide range of industries were classified under this typology such as biotechnology and pharmaceutical (5 companies), food (3), mining (2), energy distribution (2), machines and equipments (2), metal, aerospace, motorcycle, automotive, electronic, silicones, wood products. On the other hand, it was also found this sort of organizations in the service sector such as information technology (4), financial services/insurance (3), industrial and engineer services (2), hotels, resorts and restaurants (2), outsourcing services/call center, banking and health services. Therefore, results indicated that companies from distinguished business sectors were adapting their initiatives toward diversity cause.

- Engaged. This quadrant encompasses the sort of companies that show a serious commitment to diversity cause by means of statistics, painstaking statements, and other materials posted on their websites. Indeed, the engaged companies appear to fully embrace the diversity mentality and work hard toward implementing it. However, findings showed that the engaged organizations were only the third group in the sample (10.8\%). Again, such a result denotes that diversity is not a priority issue for the main organizations to work for in Brazil. Taken together, the organizations that pertained to this dimension employ together 42,812 workers. Twelve companies of this group were large ones whereas only two were considered as middle ones (i.e., middle multinational companies). Therefore, no middle domestic Brazilian organization was found in this category. Moreover, the higher employer of this dimension employed 8,746 workers, whereas the lower one employed just 187. The companies that fitted into the engaged frame employed, on average, 3,058 employees. Findings revealed that a great variety of industries took part of this quadrant such as biotechnology and pharmaceutical (3), food (2), consumer goods (2), food and beverage, chemical, metal and machines. But it was also identified technology information (2) and hotel/restaurants.

- Cynicism. This embraces companies that are clearly trying to sell a corporate image of practicing DM, but their policies just accommodate to law at best. Taken as a whole, they exhibit inconsistency with diversity discourse. Such a quadrant was the smaller group of this taxonomy, that is, $6.0 \%$ of the sample. However, the companies that fitted into this profile employed 132,968 workers. This group was made up of four large companies and four middle multinational ones likewise. The higher employer of this typology employed 84,381 workers (a financial services firm), whereas the lower one employed just 351. The companies that embraced the adaptation profile employed, on average, 16,621 employees. In sum, the companies of the sample that still demonstrated a cynic facet were from beverage and food (3), hotels, restaurants/food services, financial services, electronic industry, agriculture, forestry and fish farming industry, and information technology sector. 


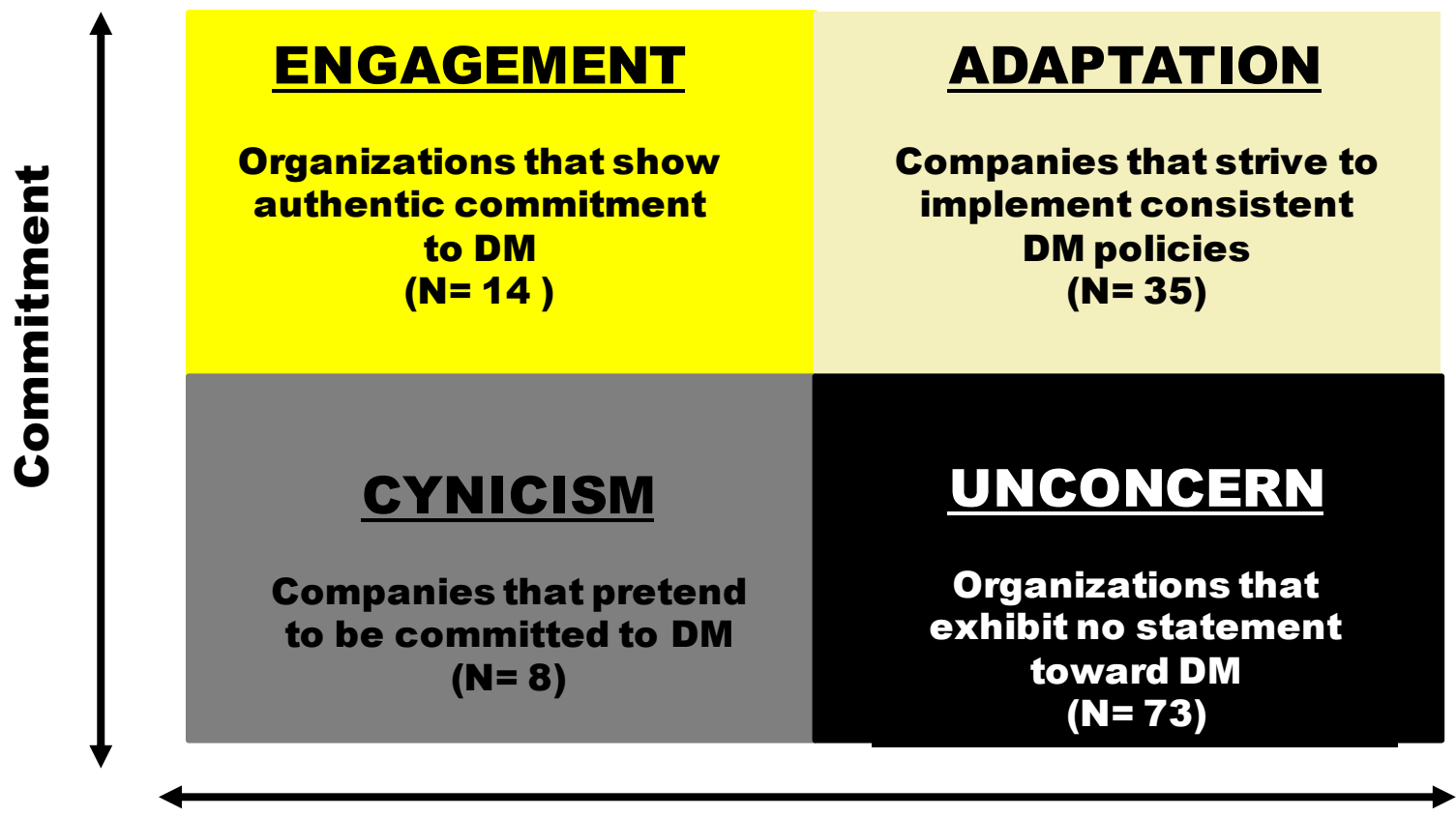

\section{Inconsistencies/Need of Improvements}

Figure 2. Taxonomy of organizations' diversity management

Source: Author's own representation.

Importantly, the findings presented here are exclusively grounded on a specific cohort of the organizations operating in Brazil. In this regard, the conclusions cannot be generalized, given the features of this qualitative study. As noted earlier, in order to ensure the reliability of the data analysis, the author invited another researcher to review the general coding process and conclusions.

\section{Conclusions}

Taken as a whole, results suggest that diversity appears to be a topic of low status in the most of the best organizations to work for in Brazil. As noted earlier, findings are consistent with previous studies undertook in that country. However, it must be pointed out again that such conclusions are undergirded exclusively by the discursive elements available on websites. In general, multinational corporations tend to put aside desirable aspects on their statements, even so they enact better diversity, inclusion, and antidiscrimination discourses than Brazilian firms. On the other hand, it is likely that many other initiatives were being carried out by the sample firms, which this investigation could not assess due to its methodology. There are certain aspects in the websites that may be better manageable. For instance, many websites did not provide a map related to the subjects or even a searching mechanism that could facilitate investigations. These are cornerstone variables that could be easily handled by companies. Corporate websites are the locus that must reflect what companies indeed value, believe, and do. Thus, organizations should behave more proactively by enriching them with a lot of information, data, and accomplishments in a well-organized way. After all, they are key channels of organizational communication and, as such, they should be easily navigable as well as be accurate in terms of statements, given that they are usually the first contact between stakeholders and the companies. 
Furthermore, all information related to diversity, inclusion, and discrimination topics should be presented in a clear way given that they are subjects that impact the corporation image. Therefore, future studies could examine the most admired and/or 500 larger companies of Brazil. I also envision that a longitudinal study would be welcomed in order to ascertain advancements or setbacks. Researchers could peruse minorities' and diversity managers' opinions by employing larger samples from specific business sectors. Researchers could examine if diversity managers have had enough power to leverage decisions on this topic, what indicators are used, and what firms really intend to implement. These are some research questions waiting for answers. At last, future investigations could also explore in larger samples the taxonomy was found in the current study. Overall, one could have a broader picture of organizational diversity profile in Brazil.

\section{Notes}

1. It was assumed that several companies could not be emphasizing the diversity issue through their websites. In these cases, I searched for other-related themes, namely, inclusion and discrimination.

2. I drew upon the list of 2013 winners because it was the last list available (Época, 2014) at the time that this investigation was undertaken.

3. Just a few organizations provided English statements. As a result, the majority of translations are mine. In this sense, any error must be attributed to the author of this study.

\section{References}

Armstrong, C., Flood, P.C., Guthrie, J.P., Liu, W., MacCurtain, S., and Mkamwa, T. (2010), "The impact of diversity and equality management on firm performance: beyond high performance work systems", Human Resource Management, Vol. 49, No. 6, pp. 977-998.

Bjerregaard, T. and Lauring, J. (2013), "Managing contradictions of corporate social responsibility: the sustainability of diversity in a frontrunner firm", Business Ethics: A European Review, Vol. 22, No. 2, pp. 131-142.

Calo, T.J. (2008), "Talent management in the era of the aging workforce: the critical role of knowledge transfer", Public Personnel Management, Vol. 37, No. 4, pp. 403-416.

Cepellos, V.M. e Tonelli, M.J. (2017), "Envelhecimento profissional: percepções e práticas de gestão da idade", Revista Alcance, Vol. 24, No. 1, pp. 4-21.

Cole, B.M. and Salimath, M.S. (2013), "Diversity identity management: an organizational perspective", Journal of Business Ethics, Vol. 116, No. 1, pp. 151-161.

Cox, T.H., Jr. and Blake, S. (1991), "Managing cultural diversity: implications for organizational competitiveness", Academy of Management Executive, Vol. 5, No. 3, pp. 45-56.

Crampton, S.M. and Hodge, J.W. (2007), "Age discrimination and downsizing", The Business review, Vol. 7, No. 1, pp. 341-347.

Demuijnck, G. (2009), "Non-discrimination in human resources management as a moral obligation", Journal of Business Ethics, Vol. 88, No. 1, pp. 83-101.

Dreachslin, J.L. (2007), "The role of leadership in creating a diversity-sensitive organization", Journal of Healthcare Management, Vol. 52, No. 3, pp. 151-155. 
Ely, R.J. and Thomas, D.A. (2001), "Cultural diversity at work: the effects of diversity perspectives on work group processes and outcomes", Administrative Science Quarterly, Vol. 46, No. 2, pp. 229-273.

Época (2014), As 130 melhores empresas para trabalhar 2014/2015.

Fairhurst, G.T. and Putnam, L. (2004), "Organizations as discursive constructions", Communication Theory, Vol. 14, No. 1, pp. 5-26.

Fasterling, B. and Demuijnck, G. (2013), "Human rights in the void? Due diligence in the UN guiding principles on business and human rights", Journal of Business Ethics, Vol. 116, No. 4, pp. 799-814.

Fleury, M.T.L. (1999), "The management of culture diversity: lessons from Brazilian companies", Industrial Management \& Data Systems, Vol. 99, No. 3, pp. 109-114.

Fleury, M.T.L. (2000), "Gerenciando a diversidade cultural: experiências de empresas brasileiras", Revista de Administração de Empresas, Vol. 40, No. 3, pp. 18-25.

Gelfand, M.J., Nishii, L.H., Raver, J.L., and Schneider, B. (2005), "Discrimination in organizations: an organizational-level systems perspective", in: Dipboye, R.L. and Colella, A. (eds.), Discrimination at work: the psychological and organizational bases, pp. 89-116, Lawrence Erlbaum Associates, New Jersey.

Gonzalez, J.A. and DeNisi, A.S. (2009), "Cross-level effects of demography and diversity climate on organizational attachment and firm effectiveness", Journal of Organizational Behavior, Vol. 30, No. 1, pp. 21-40.

Groggins, A. and Ryan, A.M. (2013), "Embracing uniqueness: the underpinnings of a positive climate for diversity", Journal of Occupational and Organizational Psychology, Vol. 86, No. 2, pp. 264-282.

Guerrier, Y. and Wilson, C. (2011), "Representing diversity on UK company web sites", Equality, Diversity and Inclusion, Vol. 30, No. 3, pp. 183-195.

Herdman, A.O. and McMillan-Capehart, A. (2010), "Establishing a diversity program is not enough: exploring the determinants of diversity climate", Journal of Business and Psychology, Vol. 25, No. 1, pp. 39-53.

Heres, L. and Benschop, Y. (2010), "Taming diversity: an exploratory study on the travel of a management fashion", Equality, Diversity and Inclusion, Vol. 29, No. 5, pp. 436-457.

Irigaray, H.A.R. e Vergara, S.C. (2011), “O tempo como dimensão de pesquisa sobre uma política de diversidade e relações de trabalho", Cadernos EBAPE.BR, Vol. 9, No. 4, pp. 1095-1098.

Jabbour, C.J.C., Gordono, F.S., Oliveira, J.H.C., Martinez, J.C., and Battistelle, R.A.G. (2011), "Diversity management: challenges, benefits, and the role of human resource management in Brazilian organizations", Equality Diversity and Inclusion, Vol. 30, No. 1, pp. 58-74.

Jayne, M.E.A. and Dipboye, R.L. (2004), "Leveraging diversity to improve business performance: research findings and recommendations for organizations", Human Resource Management, Vol. 43, No. 4, pp. 409-424.

Jørgensen, M. and Phillips, L.J. (2002), Discourse Analysis as Theory and Method, Sage: London.

Joshi, A. and Jackson, S.E. (2003), "Managing workforce diversity to enhance cooperation in organizations", in: West, M.A., Tjosvold, D., and Smith, K.G. (eds.), International handbook of organizational teamwork and cooperative working, pp. 277-296, Wiley, New York. 
Kaplan, D.M., Wiley, J.W., and Maertz, C.P., Jr. (2011), "The role of calculative attachment in the relationship between diversity climate and retention", Human Resource Management, Vol. 50, No. 2, pp. 271-287.

Kulik, C.T. (2014), "Working below and above the line: the research-practice gap in diversity management", Human Resource Management Journal, Vol. 24, No. 2, pp. 129-144.

Linnehan, F., Chrobot-Mason, D., and Konrad, A.M. (2006), "Diversity attitudes and norms: the role of ethnic identity and relational demography", Journal of Organizational Behavior, Vol. 27, No. 4, pp. 419-442.

McKay, P.F., Avery, D.R., Liao, H., and Morris, M.A. (2011), “Does diversity climate lead to customer satisfaction? It depends on the service climate and business unit demography", Organization Science, Vol. 22, No. 3, pp. 788-803.

Mena, S., de Leede, M., Baumann, D., Black, N., Lindeman, S., and McShane, L. (2010), "Advancing the business and human rights agenda: dialogue, empowerment, and constructive engagement", Journal of Business Ethics, Vol. 93, No. 1, pp. 161-188.

Meriläinen, S., Tienari, J., Katila, S., and Benschop, Y. (2009), "Diversity management vs. gender equality: the Finnish case", Canadian Journal of Administrative Sciences, Vol. 26, No. 3, pp. 230-243.

Murphy, M. and Vives, J. (2013), "Perceptions of justice and the human rights protect, respect, and remedy framework", Journal of Business Ethics, Vol. 116, No. 4, pp. 781-797.

Ng, E.S. and Sears, G.J. (2012), "CEO leadership styles and the implementation of organizational diversity practices: moderating effects of social values and age", Journal of Business Ethics, Vol. 105, No. 1, pp. 41-52.

Ng, E.S.W. and Wyrick, C.R. (2011), "Motivational bases for managing diversity: a model of leadership commitment", Human Resource Management Review, Vol. 21, No. 4, pp. 368-376.

Nóbrega, B.A., Santos, J.N., e Jesus, G.L. (2014), “Um estudo da relação entre diversidade, criatividade e competitividade em organizações brasileiras", Revista de Ciências da Administração, Vol. 16, No. 39, pp. 194-209.

Olsen, J.E. and Martins, L.L. (2012), "Understanding organizational diversity management programs: a theoretical framework and directions for future research", Journal of Organizational Behavior, Vol. 33, No. 8, pp. 1168-1187.

Özbilgin, M. and Tatli, A. (2011), "Mapping out the field of equality and diversity: rise of individualism and voluntarism", Human Relations, Vol. 64, No. 9, pp. 1229-1253.

Pedersen, E.R. (2010), "Modelling CSR: how managers understand the responsibilities of business towards society", Journal of Business Ethics, Vol. 91, No. 2, pp. 155-166.

Pereira, J.B.C., Almeida, A.P., Cordeiro, J.G., Cestari, M.M.J., Alencar, L.Q., e Mendonça Neto, A.L. (2012), "A percepção de justiça organizacional distributiva diante de ações que oferecem recursos e oportunidades à diversidade", Revista Eletrônica de Ciência Administrativa, Vol. 11, No. 1, pp. 143-161.

Phillips, N., Lawrence, T.B., and Hardy, C. (2004), "Discourse and institutions", Academy of Management Review, Vol. 29, No. 4, pp. 635-652.

Point, S. and Singh, V. (2003), "Defining and dimensionalising diversity: evidence from corporate websites across Europe”, European Management Journal, Vol. 21, No. 6, pp. 750-761.

Rabl, T. and Triana, M. del C. (2014), "Organizational value for age diversity and potential applicants' organizational attraction: individual attitudes matter", Journal of Business Ethics, Vol. 121, No. 3, pp. 403-417. 
Riach, K. (2009), “Managing 'difference': understanding age diversity in practice”, Human Resource Management Journal, Vol. 19, No. 3, pp. 319-335.

Richard, 0.C., Barnett, T., Dwyer, S., and Chadwick, K. (2004), "Cultural diversity in management, firm performance and the moderating role of entrepreneurial orientation dimensions", Academy of Management Journal, Vol. 47, No. 2, pp. 255266.

Richard, O.C. and Johnson, N.B. (2001), "Understanding the impact of human resource diversity practices on firm performance", Journal of Managerial Issues, Vol. 13, No. 2, pp. 177-195.

Roberge, M.-É., Lewicki, R.J., Hietapelto, A., and Abdyldaeva, A. (2011), "From theory to practice: recommending supportive diversity practices", Journal of Diversity Management, Vol. 6, No. 2, pp. 1-20.

Roberson, L. and Kulik, C.T. (2007), "Stereotype threat at work", Academy of Management Perspectives, Vol. 21, No. 2, pp. 24-40.

Roberson, Q.M. and Park, H.J. (2007), "Examining the link between diversity and firm performance: the effects of diversity reputation and leader racial diversity", Group \& Organization Management, Vol. 32, No. 5, pp. 548-568.

Santos, G.C.M., Rodrigues, I., Dutra, S.E., e Costa, B.V.L. (2008)," Gestão da diversidade: um estudo entre "as melhores empresas para você trabalhar", in: XI SEMEAD Seminários de Administração, São Paulo. XI SEMEAD - Empreendedorismo em Organizações.

Saraiva, L.A.S. e Irigaray, H.A.R. (2009), "Políticas de diversidade nas organizações: uma questão de discurso?", Revista de Administração de Empresas, Vol. 49, No. 3, pp. 337-348.

Sawyerr, 0.0., Strauss, J., and Yan, J. (2005), "Individual value structure and diversity attitudes: the moderating effects of age, gender, race, and religiosity", Journal of Managerial Psychology, Vol. 20, No. 5/6, pp. 498-521.

Singh, V. and Point, S. (2004), "Strategic responses by European companies to the diversity challenge: an online comparison", Long Range Planning, Vol. 37, No. 4, pp. 295-318.

Singh, B. and Selvarajan, T.T. (2013), "Is it spillover or compensation? Effects of community and organizational diversity climates on race differentiated employee intent to stay", Journal of Business Ethics, Vol. 115, No. 2, pp. 259-269.

Stewart, R., Volpone, S.D., Avery, D.R., and McKay, P. (2011), "You support diversity, but are you ethical? Examining the interactive effects of diversity and ethical climate perceptions on turnover intentions", Journal of Business Ethics, Vol. 100, No. 4, pp. 581-593.

Syed, J. and Kramar, R. (2009), "Socially responsible diversity management", Journal of Management \& Organization, Vol. 15, No. 5, pp. 639-651.

Tatli, A. (2010), "Discourses and practices of diversity management in the UK", in: Klarsfeld, A. (ed.), International handbook on diversity management at work: country perspectives on diversity and equal treatment, pp. 283-303, Edward Elgar, Cheltenham.

Tatli, A. (2011), "A multi-layered exploration of the diversity management field: diversity discourses, practices and practitioners in the UK", British Journal of Management, Vol. 22, No. 2, pp. 238-253.

Triana, M. del C., Wagstaff, M.F., and Kim, K. (2012), “That's not fair! How personal value for diversity influences reactions to the perceived discriminatory treatment of minorities", Journal of Business Ethics, Vol. 111, No. 2, pp. 211-218. 
Turnbull, H., Greenwood, R., Tworoger, L., and Golden, C. (2010), "Skill deficiencies in diversity and inclusion in organizations: developing am inclusion skills measurements", Academy of Strategic Management Journal, Vol. 9, No. 1, pp. 1-13.

van Dick, R., van Knippenberg, D., Hägele, S., Guillaume, Y.R.F., and Brodbeck, F.C. (2008). Group diversity and group identification: the moderating role of diversity beliefs. Human Relations, Vol. 61, No. 10, pp. 1463-1492.

van Knippenberg, D. and Schippers, M.C. (2007), "Work group diversity", Annual Review of Psychology, Vol. 58, pp. 515-541.

Vasconcelos, A. F. (forthcoming), Talentos Maduros, Diversidade e Inclusão: Uma Visão Crítica, Editora da UFRGS: Porto Alegre.

Vasconcelos, A.F. (2012), "Ageism: a study of the demographic diversity in Brazil", Management Research, Vol. 10, No. 3, pp. 187-207.

Vasconcelos, A.F. (2016a), "Organizations workforce demographic age preferences: multiple case-studies from Brazil”, Journal of Management Development, Vol. 35, No. 3, pp. 406-427.

Vasconcelos, A.F. (2016b), "Mapping Brazilian workforce diversity: a historical analysis", Management Research Review, Vol. 39, No. 10, pp. 1352-1372.

Wallace, H.M.L., Hoover, K.F., and Pepper, M. B. (2014), "Multicultural ethics and diversity discourse", Equality, Diversity and Inclusion, Vol. 33, No. 4, pp. 318-333.

Weaver, D. (2008), "Managing diversity", in: Kinder, A., Hughes, R., and Cooper, C.L. (eds.), Employee well-being support: a workplace resource, pp. 111-118, John Wiley \& Sons, West Sussex.

Wiernik, B.M., Ones, D.S., and Dilchert, S. (2013), “Age and environmental sustainability: a meta-analysis", Journal of Managerial Psychology, Vol. 28, No. 7/8, pp. 826-856.

Zanoni, P. and Janssens, M. (2015), "The power of diversity discourses at work: on the interlocking nature of diversities and occupations", Organization Studies, Vol. 36, No. 11, pp. 1463-1483. 